\title{
Effect of implementation quadruple glazing panel into the walls on the airborne sound insulation of building facades
}

\author{
Pavel Drabek ${ }^{1, *}$ \\ ${ }^{1}$ Tomas Bata University in Zlin, Faculty of Applied Informatics, Department of Automation and Control Engineering, Nad Stranemi \\ 4511, Czech Republic
}

\begin{abstract}
Noise is one of the major national problems for decades. In the case of buildings, this concernment has become an issue when building structures are becoming lighter and lighter in weight. This approach does not only caused difficulties with poor sound insulation but also meant heat accumulation problems. This is due to the fact that commonly used lightweight construction materials are not able to absorb too much heat energy like massive constructions did. Production and implementation companies are trying to avoid these ailments by implementing accumulation materials into the buildings most frequently in the form of panels. A subject of this paper is to study the effect of implementation one type of facade system into the perimeter walls on the airborne sound insulation of building facades. The research is dedicated to the quadruple glazing panel which is a translucent wall element without any mechanical components or electronic devices.
\end{abstract}

\section{Introduction}

The general building rule is that all parts of the building must work altogether. Without the correlation between construction elements and technological equipment, the buildings are bound to have some serious defects. Therefore the individual elements which are implemented into the building must have specific properties even in terms of acoustics. In recent years the construction of lightweight buildings has grown and the sound insulation of these structures has become a serious trouble.

The sound is transmitted through most walls and floors by setting the entire structure into vibration. This vibration generates new sound waves of reduced intensity on the other side [1]. For single leaf structures, such as a homogenous concrete wall, the transmission follows the mass law, that is, the more massive the structure, the smaller the quantity of transmitted sound [2]. In case of lightweight structures consisting of multiple layers, such as a gypsum wall, the spring-mass law is applicable. If a highly absorbent material such as stone wool is used as the spring in a double leaf wall, the sound insulation improves. This fact was one of the reasons why manufacturers have started using a multilayer sandwich structures in lightweight buildings. Thus, the sound insulation structures have begun to improve over the years. However, the acoustics were not the only issue that required attention. In previous research [3], we studied the effect of the thermal accumulation on the energy efficiency of the building. One of the research intentions was to solve the light constructions and their thermal accumulation abilities which are lower compared to the more massive structures. Consequently, the energy consumption of lightweight buildings may be higher than an identical building with higher thermal accumulation. For this reason, production and implementation companies increase thermal accumulation by installing mostly PCM materials into perimeter walls.

This paper deals with the passive facade system in the form of transparent wall elements which increases both the thermal capacity of the rooms and the thermal comfort. These elements are installed instead of nonload-bearing perimeter walls. The aim of this work is to determine the impact of installation of these elements on the overall airborne sound insulation of the facade.

\section{Internal environment parameters}

Sound transmission paths through the structure are of diverse character. The requirements for noise level in rooms which further affect the properties of the façade are derived from the Ministry of Health decree which requires fulfilment of the two parameters, the equivalent noise level $L_{\text {Aeq }}$ and the maximum noise level $L_{\text {Amax }}$. For the transmission of sound, only the structural features of the facade are not decisive but also the sound behaviour inside the space has a certain effect because multiple reflections from the walls, ceiling, floor, and object surfaces influence the sound pressure level [1]. Valid values of $L_{\mathrm{Aeq}}$ in front of the facade and in the internal area are listed in Table 1 . In the context of this article, living rooms were preferred to be studied, since the inner environment requirements for this type of interior space

* Corresponding author: pdrabek@fai.utb.cz 
places more emphasis on $L_{\mathrm{Amax}}$ value than to other types of indoor areas, with the exception of hospital rooms.

Table 1. The parameters considered for the noise analysis [4].

\begin{tabular}{|l|c|c|}
\hline \multicolumn{2}{|l|}{$\boldsymbol{L}_{\text {Aeq, }}[\mathbf{d B}]$ two meters in front of the facade } \\
\hline \multirow{2}{*}{$\begin{array}{l}\text { Highways, roads I. and II. class, local } \\
\text { roads I. and II. cl. }\end{array}$} & Day time: & $65 \mathrm{~dB}$ \\
\cline { 2 - 3 } & Night time: & $55 \mathrm{~dB}$ \\
\hline \multirow{2}{*}{$\boldsymbol{L}_{\mathrm{Amax}}[\mathbf{d B}]$ of indoor areas } & Day time: & \multirow{2}{|c|}{$40 \mathrm{~dB}$} \\
\hline \multirow{2}{*}{ Living rooms } & Night time: & $30 \mathrm{~dB}$ \\
\cline { 2 - 3 } Required sound insulation value of facade $\boldsymbol{R} \mathbf{w}[\mathbf{d B}]$ \\
\hline \multirow{2}{*}{ Living rooms } & Day time: & $33 \mathrm{~dB}$ \\
\cline { 2 - 3 } & Night time: & $33 \mathrm{~dB}$ \\
\hline
\end{tabular}

\section{Quadruple glazing panel}

The relevant task described in the article was to evaluate theoretical and experimental aspects of acoustic properties such as airborne sound insulation and reflection of sound waves of the panel. From the point of view of acoustics, this panel can be described as glazing group of multiple safety glasses without a frame. This group contains hermetically sealed cavities filled with inert gas, prism plate and PCM material (see Fig. 1). The entirety of these elements is ensured by a structural sealant, which stands for the frame of the whole set. It can be obvious that even the type of connection method affects the acoustic properties of the whole element.

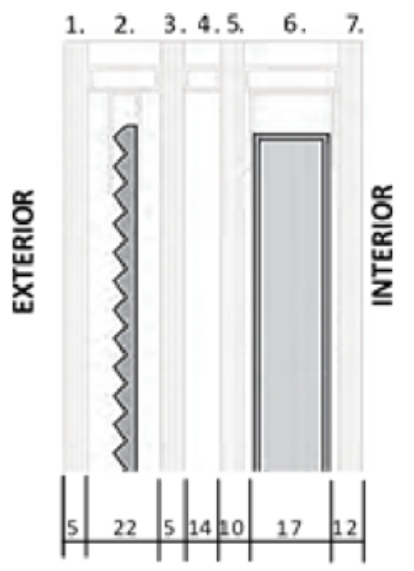

1. Tempered safety glass

2. Prism plate and inert gas

3. Tempered safety glass

4. Inert gas

5. Tempered safety glass

6. PCM plate

7. Clear glass

Note: The image may not correspond to the measured dimensions.

Fig. 1. Description of layers of quadruple glazing panel.

The transmission of sound energy through the weakest elements of the façade, especially the windows, is mainly due to the vibration of the glazed parts [2]. With the area density and the observed frequency, the degree of sound insulation is also changing or, more specifically, with increasing area density, airborne sound insulation also increases because the window surface is no longer so easy to vibrate, and at the same time, the amount of scattering of the incident sound energy from the surface of the window increases [1][2]. The airborne sound rate also affects the angle of the incident sound waves, discontinuities, stiffness, the number of windows and so on. However, these general assumptions are not fully applicable to a building element of this type.

Generally, the degree of airborne sound insulation is mainly dependent on the area density of the glass. Based on experimental measurements, it was found that the airborne sound insulation of a single glass only slightly increases from $6.5 \mathrm{~kg} / \mathrm{m}^{-2}$ due to coincidence effect in the soundproofing area [2][5]. For double glazing with significantly different glass thicknesses, the coincidence of the thicker glass is already suppressed. And in the case of triple glazing the positive effect is reflected mainly at higher frequencies, and in the case of frequencies smaller than $500 \mathrm{~Hz}$, the improvement is minimal [5][6]. However, the design of this panel is different from the common windows described above. The absence of the frame, the connection method and the window surface greatly change the acoustic properties [2]. The area density of individual glasses ranges from 12.5 to $30 \mathrm{~kg} / \mathrm{m}^{-2}$ and the dimensions of the panel are 1.2 $\mathrm{x} 1.2 \mathrm{~m}$. From a general perspective, the panel acts as a very heavy and rigid building component. The calculated critical frequency is around $150 \mathrm{~Hz}$. This relatively low value, combined with different glass and gauge thicknesses, means that the coincidence effect is almost completely suppressed here.

\section{Methods}

The level of airborne sound insulation of the facade can be solved in several ways. The basic ones are computational models, simulation models and real measurements in the laboratory. The solution in this article is based on computational models which reflect experiences of predicting sound transmission through the facade of residential buildings and other building of a similar character [7]. The accuracy of such models depends on the accuracy of the input data, the model situation, the type of façade elements contained, the geometry of the situation and the type of the predicted variable. Likewise, the different types of external sound field used in different situations lead to different values [7]. For this reason, only the incident of the diffuse sound field was considered, because it is rationally assumed that the results are sufficiently representative for other types of external sound fields. Another important aspect for predicting the noise load in an indoor area is also the spectral character of the attenuation of sound propagation in the outdoor environment [8]. This attenuation occurs as a result of the absorption of sound in the atmosphere and its magnitude depends on specific meteorological conditions. All these parameters require the attention of acoustical engineers. The input values entering the analysis were obtained by measuring the standardized 
sound pressure level difference in the laboratory. These concernments will be discussed in the following.

\subsection{Laboratory measurement of acoustic parameters}

Airborne sound insulation measurements were performed according to the requirements of the concerned standards [8][9]. For the measurement itself, a special chamber was used, the interior space of which was divided into two parts (outdoor and indoor) by a dividing partition and a wall opening for a panel was created in it. Subsequently, wall diffusion elements were placed in the outdoor room to form a partial diffusion field at a frequency range of $50-10000 \mathrm{~Hz}$ and there was also a sound source in the room. The already built-in panel has been further modified from the indoor side so that the individual microphones can be firmly attached close to the window surface. At the same time, it was desirable to minimize the influence of lateral transmission, in particular reflections from the back wall of the indoor room. For this reason, the microphones were placed in the air gap between the panel and the board with absorbent material (see Fig. 2). Afterwards, on both sides, the average sound pressure levels in the third-octave bands at the aforementioned frequency range were measured.

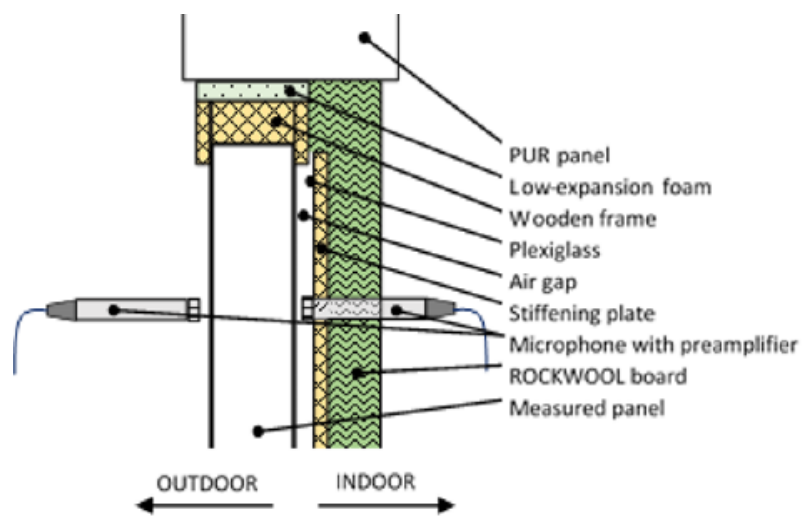

Fig. 2. Schematic representation of microphone mounts with rear-side absorption.

In the experimental measurement, only the normalized difference in sound pressure levels for the entire frequency range was found. These values need to be attributed to the influence of lateral transmission, which is also frequency dependent; however, this influence has not yet been accurately determined. Due to the risk of considerable transmission of acoustic energy by the dividing partition, an "orientation" test was conducted to determine if the acoustic power transmitted by the surrounding structure is small compared to the acoustic power transmitted over the test element. The result of this test was that the acoustic energy transmitted by the partition is even higher than the acoustic energy transmitted by the test element; consequently, it is necessary to modify the existing partition between indoor and outdoor space by installing additional material which would bring a high weight to a small thickness.

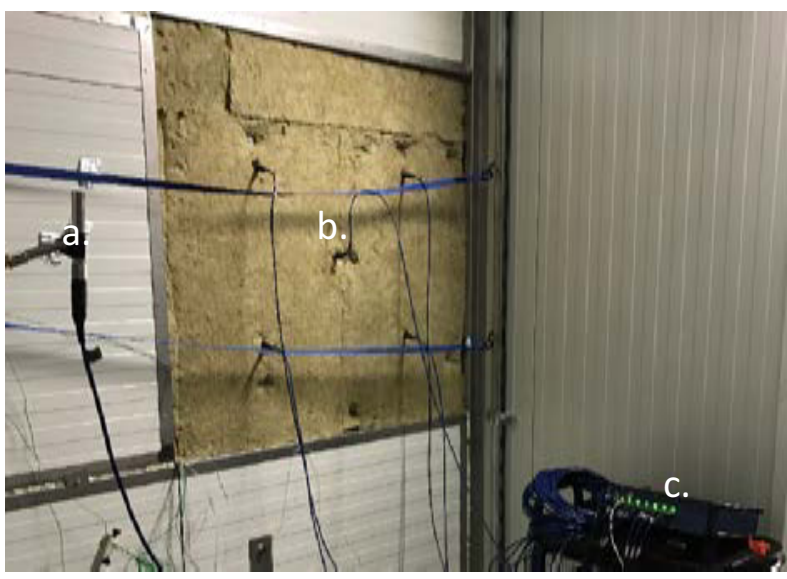

Fig. 3. Measurement of the standardized level difference in the Laboratory (a. LpA measurement in reception room, b. Microphone field, c. Norsonic MF-850).

\subsection{Model situation description}

To process this point, the internal area of the administration building was taken into account. The dimensional parameters of the considered area are shown in Table 2.

Table 2. Dimensional specifications of the considered area.

\begin{tabular}{|c|c|}
\hline \multicolumn{2}{|l|}{ Room Parameters } \\
\hline Dimensions in [m], (w x $1 \mathrm{x} h)$ & $7,32 \times 8,70 \times 3,01$ \\
\hline Surface in $\left[\mathrm{m}^{2}\right]$ & 223,81 \\
\hline Volume in $\left[\mathrm{m}^{3}\right]$ & 191,69 \\
\hline \multicolumn{2}{|c|}{$\begin{array}{l}\text { Parameters of the wall in contact with the outdoor } \\
\text { environment }\end{array}$} \\
\hline Inner surface in $\left[\mathrm{m}^{2}\right]$ & 26,19 \\
\hline Windows surface in $\left[\mathrm{m}^{2}\right]$ & 13,51 \\
\hline Windows frame surface in $\left[\mathrm{m}^{2}\right]$ & 3,12 \\
\hline Other structures surface in $\left[\mathrm{m}^{2}\right]$ & 12,68 \\
\hline Usable surface for PCM panels & 8,00 \\
\hline
\end{tabular}

Since the full mathematical description of the acoustic insulation conferred by glazed panels is extremely complicated, simplified theoretical models are frequently used [1][7]. As the predominant source of sound in the outdoor environment, the most frequent source of outdoor noise, road traffic was considered. For this situation, were served the standard values of the sound pressure levels for transport density (1000 cars/hour), which were subsequently recalculated to a reference distance of $30 \mathrm{~m}$ (the distance of the linear source and the facade of the model situation). Subsequently, it was 
necessary to determine the considered frequency range, which is prominent for the given situation. This range depends primarily on the magnitude of attenuation due to its absorption in the atmosphere for different weather conditions [10].

The very spectral nature of the attenuation of sound propagation in the outdoor environment is very important in the prediction of the noise pollution in indoor space. The output is the value of the attenuation coefficient $\mathrm{m}$. Thus, attenuations in the frequency bands for the given atmospheric conditions were determined at first. From these attenuations, the sound pressure levels at the reference distance were determined, to which additional losses were added to the reference distance, and subsequently, the sound pressure level $L_{\mathrm{pA}}$ in front of the facade was determined. Consequently, the upper limit of the frequency range has been reduced to $4 \mathrm{kHz}$. Higher frequencies do not need to be taken into account due to atmospheric attenuation and the fact that almost all building materials are characterized by high absorption or reflection capabilities at this frequency range [10].

In order to calculate the effect of quadruple glazing panel implementation on airborne sound insulation, experimentally determined values of domestic certified laboratories were used, these values are shown in Table 3.

Table 3. The acoustic data of the implemented elements in the model situation

\begin{tabular}{|l|c|c|c|c|c|c|}
\hline \multirow{2}{*}{ Element used } & \multicolumn{5}{|c|}{ Frequency [Hz] } \\
\cline { 2 - 7 } & 125 & 250 & 500 & 1000 & 2000 & 4000 \\
\cline { 2 - 7 } & \multicolumn{5}{|c|}{ Airborne sound insulation $R$ w [dB] } \\
\hline $\begin{array}{l}\text { Sandwich wall of } \\
\text { thickness 30 cm }\end{array}$ & 35 & 40 & 46 & 52 & 58 & 64 \\
\hline $\begin{array}{l}\text { Double glazing } \\
\text { Window (6/16/6) }\end{array}$ & 23 & 22 & 30 & 36 & 37 & 39 \\
\hline $\begin{array}{l}\text { Quadruple glazing } \\
\text { panel }\end{array}$ & 25 & 27 & 28 & 31 & 41 & 51 \\
\hline
\end{tabular}

\section{Results}

In the following the results of the measurement of the standard difference of the sound pressure levels as well as the results of the model situation are summarized.

In general, the main parameter describing the listening parameters of the room is the reverberation time [1]. It is dependent on several input parameters, of which the dimensions of the room and the sound absorption of the internal surfaces are of utmost importance. The maximum value of the sound absorption factor depends mainly on the sound absorption coefficient [2]. As this factor is higher, the higher the absorption can be achieved. Whilst on how material absorbs in the range of lower frequencies is determined primarily by its thickness and that is why the sound absorption value of the panel at low frequencies is considerably lower than the sandwich wall type. In the range of higher frequencies, the sound absorption of the panel is very similar to lower frequencies.

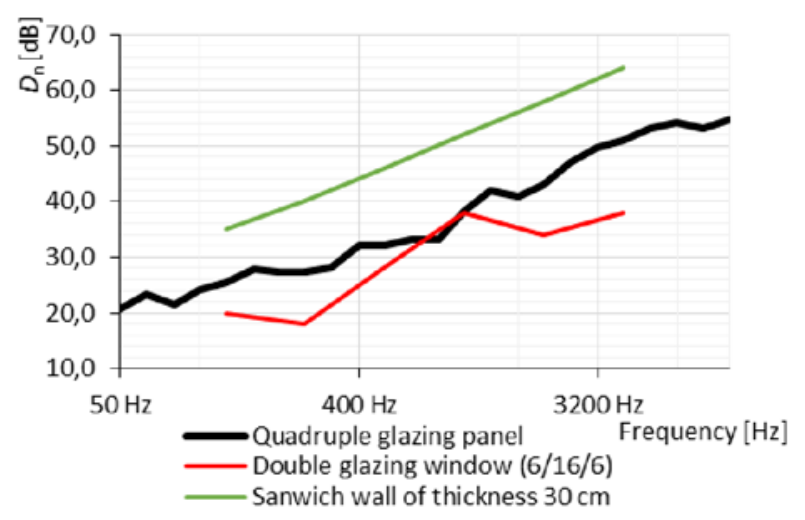

Fig. 3. Description of layers of quadruple glazing panel.

Based on this fact, it can be stated that the implementation of PCM windows into the perimeter walls will not have a significant negative impact on the overall listening parameters of the room (see Fig. 4); however, from the point of view of the soundproofing properties, it is necessary to ensure the proper fit and seal because the individual joints and gaps are the weakest facade elements.

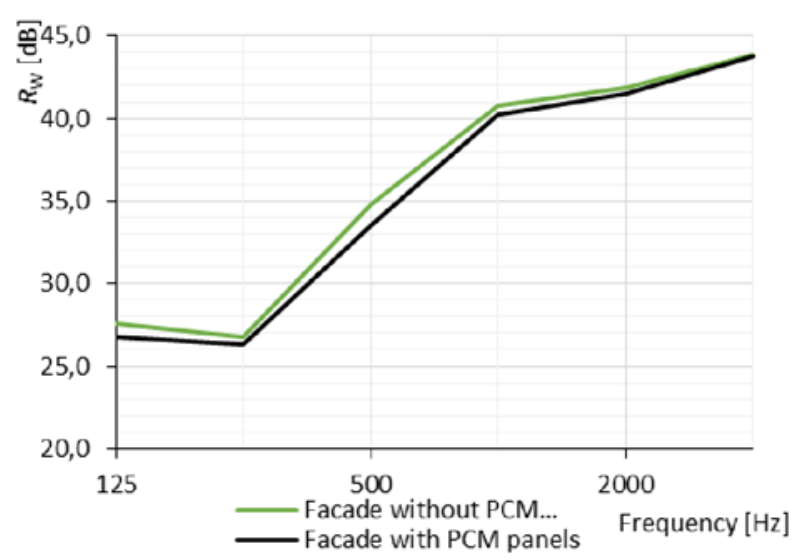

Fig. 4. Influence of quadruple glazing panel implementation on airborne soundness in the model situation.

\section{Conclusion}

Sound insulation between the different rooms inside a building or to the outside environment is a very complex problem [11][12]. This matter has become very topical in the recent years mainly in connection with the development of buildings constructed from lightweight materials. The aim of the study was to determine the impact of the implementation of the quadruple glazing panel with the PCM plate into the perimeter walls, instead of non-load-bearing structures, on the sound insulation properties of the facade. This goal was met with the authors' comments and that the results of the experimental measurement do not include the effect of the sound transmission by the sideways which must be added to the value of the standard difference $D_{\mathrm{n}}$. To determine the rate of sound transmission by sideways it would be necessary to install an element of known 
acoustic parameters in the reduced aperture, and a substitution method could be used to determine it. The conclusion is that the correct incorporation of these types of storage elements into the perimeter walls of buildings will not significantly reduce the sound-insulating properties.

\section{Acknowledgement}

This work was supported by the Ministry of Education, Youth and Sports of the Czech Republic within the National Sustainability Programme project No. LO1303 (MSMT7778/2014) and also by the Internal Grant Agency of Tomas Bata University in Zlin under the project No. IGA/CebiaTech/2017/002.

\section{References}

1. H. Kuttruff, Room Acoustics, 5, (2009)

2. M. Möser, G. Müller, Handbook of Engineering Acoustics, (2013)
3. P. Drabek, M. Zalesak, WSEAS Transactions on Systems and Control, 11, 32-38 (2016)

4. 272/2011 Sb., Regulation, Ministri, Praha (2011)

5. A. Tadeu, D. Mateus, Applied Acoustics, 62, 307325 (2001)

6. D. Vila, Master Thesis, (2012)

7. EN 12354, Standard, European Committee for Standardization, Brusel, (2001)

8. EN ISO 717-1, Standard, European Committee for Standardization, Brusel, (2013)

9. EN ISO 140-5, Standard, European Committee for Standardization, Brusel, (2000)

10. EN ISO 9613-1, Standard, European Committee for Standardization, Brusel, (1995)

11. N. Ashmore, D. Cabrera, C. Kocer, Australian Acoustical Society, N/A, 1-9 (2015)

12. R. Wareing, J. Davy, J. Pearse, Australian Acoustical Society, N/A, 1-10 (2014) 